\title{
'Role' and 'Position': Job Expectations and Practices
}

\author{
Dr Viola Wong Yuk Yue \\ The Hong Kong Polytechnic University, Hong Kong \\ E-mail: ecvwong@polyu.edu.hk
}

Received: July 7, 2011

Accepted: August 4, $2011 \quad$ Published: January 1, 2012

doi:10.5539/ass.v8n1p12

URL: http://dx.doi.org/10.5539/ass.v8n1p12

\begin{abstract}
The paper studies a middle management position at an academic institute and examines the official nature of "role" and "position" in organisational structure to discuss the distinct concepts of roles and positions in an academic context and enrich our understanding of organizational roles. Data for the investigation includes official documents from the institute and entries in a work diary. The paper describes 'role' and 'position' and examines the tension between them. It also brings to the forefront the importance of an individual's endogenous functioning disposition in the workplace situation and exogenous labelling-cum-expectations among individuals in an organisation.
\end{abstract}

Keywords: Organisational role performance, Role ambiguity, Official position tension

\section{Introduction}

Any position in an organisation carries with it its own set of expectations and attributes. A study of role and position in an organisation concerns not only just the expectations of a particular role, but also the perception of the incumbents in these roles, which is usually based on or influenced by the incumbents' predisposition and experience. Demands of an official position, workplace role expectations and opportunities, and personal perceptions of roles create a vibrant image of an individual's role in a particular position in a specific organisation. This study aims to obtain a snapshot of the functioning of a management position in the early development of a fast growing workplace to get a better understanding of the interplay between the concepts of 'role' and 'position'. It examines a middle management position in a language centre with about 60 academic staff at a university in the Hong Kong Special Administrative Region (HKSAR), and analyses the daily routine and official expectations of an academic staff member in that management position. The paper begins with a brief discussion of role and position as well as the structure and culture of an organization, to shed light on the issues involved in a discussion of role and responsibility in this study.

\subsection{The Nature of Role and Position}

Employees' positions in an organisational hierarchy are implicit in their titles or designations; however, their roles bring out the dynamics of these positions. Levinson (1959) has emphasised the difference between the concepts of role and position, stating that "a position is an element of organisational autonomy, a location in social space, a category of organisational membership. A role is .... an aspect of organisational physiology; it involves function, adaptation, process" (p.226). Goffman (1961) has also put forward a clear interpretation of the relationship between 'position' (or 'status') and 'role'.

A status is a position in some system or pattern of positions and is related to the other positions in the unit through reciprocal ties, through rights and duties binding on the incumbents. Role consists of the activity the incumbent would engage in were he to act solely in terms of the normative demands upon someone in his position (Goffman, cited in Ruddock 1969, p. 16).

In short, both Levinson and Goffman point out that an individual holds or occupies a position, but also plays or performs a role in that position and the organization.

Role can be defined from different standpoints - the definition can emphasise the job- or the task-related aspects of role, its interpersonal aspects, or how all these relate to each other. According to McKenna (2006), 'A role could be defined as a set of expected patterns of behavior attributable to a person occupying a particular position' (p. 318) and there are three distinct aspects of roles, namely expected role, perceived role and enacted role (pp. 
318-319). There is usually a detailed official description of each organisational position, which acts as an important index of the expectations of the organisation with regard to that position. Silverman (1970) has classified these expectations or job prescriptions in terms of modalities such as 'must', 'should' and 'could'. A similar continuum of compulsion has been adopted by Schein (1971), who distinguishes job role attributes as 'pivotal', 'relevant' and 'peripheral' (p.412). In other words, 'role' comprises the demands (which may include expectations, responsibilities, norms, and taboos) for a position in an organisation. Apart from this expected role, there are two more distinct aspects of role in a position: the perceived role that is developed by the position holder from the expected role, and the enacted role which refers to the way in which the position holder performs his/her perceived role (McKenna 2006, p. 318-319).

When members of an organisation perform a role or are acting 'in role', they usually interact with each other in ways that are specified within the organisation's standardised channels of communication. This behaviour would reflect in various degrees the acceptance of the chain of command (i.e. the role hierarchy), the relationship among the members of the organization with regard to their jobs (i.e. the role network), and in most cases even the expectations of people outside the organisation (i.e. the role set). The relationships and communication among members in a group help clarify the role(s) of a position. When an individual is acting 'out of role', s/he runs the risk of 'role conflict'. Role conflict occurs when there is incompatibility in demands and/or expectations, or where there are contradictory directives and perceptions of the job and its demands (Biddle 1979; Grace 1972). There is currently much research being done on the impact of role conflict and role ambiguity on middle management positions (Schaubroeck, Cotton \& Jennings, 1989; Judge, Boudrewu \& Bretz 1994; Sarros, Gmelch, $\&$ Tanewski, 1996). Individuals may encounter situations in which they have to play roles that conflict with each other or in which they experience inadequacies or uncertainties when performing their roles.

Two conceptions of 'role' are distinguishable in role discussion: structural and interactional. The structural conception of 'role' highlights the status, demands, and expectations that pertain to positions in an organisation; interactional conception stresses the dynamic aspect of the activities of a position and the behaviour of a position holder. Together the two conceptions of role bring out the characteristics of a position in a specific organisation that has its own unique structure and culture.

\subsection{Structure of an Organisation}

When Paisey (1992) discusses the political aspect of the structure of humanistic organizations, such as educational organisations, he uses the term 'loose coupling' to describe jobs, authority, and position.

... the structure of a school should closely reflect the current overall task which the school faces.... The reasons are plain: the increase in knowledge, staff and pupil turnover, the demands which parents and employers make of the curriculum, pedagogical factors and many other variables all combine to present any school with the need for continual adaptation (Paisey 1992, p. 102).

While positions are the least subject to change and give stability to the structure of an organization, jobs and authority are relatively flexible and subject to change and redistribution (Paisey, 1992). This is especially the case with an organisational structure that adopts more open responsibilities through use, multidirectional communication channels, consultation among those having related activities in their own jobs, and a participative approach to decision-making (Harrison \& Shirom, 1999). In other words, while positions (i.e. titles and designations) might appear to be permanent, jobs (which also imply responsibilities) and authority can be undergoing much change, demonstrating the dynamic nature of the positions. In the context of an educational institute such as a university, because of a wide range of expectations and increased complexity of both academic and administrative work, there may be a need to restructure academic roles, have a clearer difference between teaching and research, and promote a collective effort to enhance teaching and research activity (McInnis 1998).

\subsection{Culture of an Organisation}

Culture plays an important part in the way an organization is structured, the routine practices are carried out and the quality of work relationship among staff. When he discusses organisational culture in school, Sergiovanni (1989) puts forward the following:

Schools are not managerially tight and culturally loose, but rather are culturally tight and managerially loose. The reality is that teachers and other school workers respond much more to their values and beliefs, how they are socialized, and the norms of the work group than they do to their management controls. (p. 32)

According to Harrison \& Shirom (1999), culture in an organization “... usually refers to shared norms, values, beliefs, and assumptions concerning organisational affairs" (p. 257). Organisational culture can be viewed as an asset of assumptions and artifacts that gives personality to the organization and make members of that 
organization unique. These shared norms, values, beliefs, and assumptions then shape the organisation and underlie the interpretive processes and patterns that occur within the organisational culture. An understanding of these shared orientations and interpretations in the process of reality construction in an organisation make sense of the interactions among its members (when the members are performing their roles) in their official capacities (that is, in the positions they are holding). Variable circumstances and changing needs can re-shape the shared features of the organisational culture, necessitating a constant re-adjustment for management positions.

\subsection{Role Study}

Although learning about the role of a position holder may not be adequate to predict how other people in that position will act in a specific situation, it can shed light on what a person or a professional group in that position will generally do. A study of the roles in an organisation can reveal the meaning and interpretation constructed by the holder of a position.

Qualitative research methods are especially suitable for an interpretative orientation of role study, as they can provide a sophisticated research strategy to obtain the contextualised nature of experience and action and understand how and why people act in the way they do. In role study, individual tasks or activities carried out by a position holder and interpretations of these events relate to larger meanings and patterns in the specific context (i.e. the organisation) under study. Analysis of this rich and integrative data contributes to a comprehension of the complex creation of meaning within that context. Qualitative data are generally believed to be reliable for the investigation of creation and maintenance of meaning because they 'document the world from the point of view of the people studied' (Hammersley, 1992, p. 45).

A dominant theme in role study research is the conflicts that occur in roles. There has been research into conflict between professionals (that is, the experts of an occupation) and bureaucracy (the formal division of labour in an organisation) (Guy, 1985; Lachman \& Aranya, 1986; Sorensen \& Sorensen, 1974). With regard to managerial strategies, it has been argued that there is an inherent tension between professional and administrative culture or ethos (Raelin, 1986; Sonnenstahl \& Trice, 1991). An analysis of the role of professionals who have taken up management positions is, in fact, an examination of the interface between professionals and bureaucracy in the organization. There is also the question of whether the interface is conducive to a symbiotic or conflictual co-existence between professionals and the bureaucracy.

In theory, management has the power to influence employees' actions through the chain of command and authority in its organisational structure (Hood, 1976, McCalley, 2002). It has been argued, however, that managers who are professionals tend to manage differently because their decisions and actions can be influenced by the values, beliefs, ethics, and code of behaviour of their own profession (Ham \& Hill, 1993). Thus, academics or educators who assume management tasks usually also take on the professional tasks of acting as role models for the academic and teaching profession, producing a heavier workplace burden than that for managers in other sectors (Bates, 1998). Therefore, the implication for management in the educational community is that apart from dealing with routine administrative work, management staff has to handle activities that come primarily from the professional rather than the managerial component of their positions. A discussion of role expectations and work activities in terms of the conception of managerial work of a particular position in an educational context cannot neglect the impact of the relationship between teaching professionalism and organisational structure (or bureaucratisation).

\section{The Present Study}

To bring out the dynamic role elements found in a managerial position, the present study situated managerial work in the context of the organisational structure that shapes it. Organisational structure is a configuration of institutional arrangements (Hales, 1993) through which managerial work is carried out. The culture of a unit that is the focus of the present study is similar to Handy's (1985) description of the culture of role, in which individuals or groups of individuals are assigned a specific role. Like many educational institutes in the new millenium, the university in this study is facing many challenges that are brought on by factors such as the massification of higher education, the varied standards of student intake, the intensification of expectations from various stakeholders (employers, students, and senior management) and the strong emphasis on student-oriented pedagogy and curriculum.

This study examines a middle management position held by a university teaching professional in order to find out how an academic staff member deals with expectations from different sources at work and the roles she plays in her middle management position. The position under study is Assistant Professor at an English centre in a university in the Hong Kong Special Administrative Region (HKSAR). 
English is the major language used for instruction in most higher education institutions in the HKSAR, and there is a generally wide recognition of the importance of the English language in an academic context and in the workplace. Different approaches and systems to enhance students' English language proficiency and competence are found in universities. In many of these universities, a teaching unit (instead of an academic unit) is dedicated to the job of teaching and learning the English language. The key difference between a teaching unit and an academic unit is that most of the teachers in a teaching unit are 'instructors', whereas those in an academic unit hold the 'professorial' rank - a position that is higher than that of 'instructor'. Senior positions in a teaching unit may be held by Principal or Senior Lecturers and/or Assistant Professors. The centre of the English language discussed in this paper is an example of such a teaching unit at a university in Hong Kong.

The Centre had a teaching staff of 56, including 3 Assistant Professors at the time of this study. There were 5 senior lecturers; and the rest were language instructors. The Centre offered credit- and non-credit-bearing English language courses, such as English for Academic Purposes (EAP) and English in the Workplace (EIW) to all University students. The Centre had two additional sub-units: one offered English language enhancement programmes (ELEP); and the other, the Centre for Independent Language Learning (CILL), provided the facilities and resources for students to pursue their English studies independently. These two units supported the teaching of all courses offered by the Centre.

\subsection{Study Method}

In order to understand the complex work of an Assistant Professor in the Centre, two types of materials were examined: Official documents and the work diary of an Assistant Professor.

2.1.1 Official Documents. Official documents consulted included "Performance Expectation Guidelines", "Academic, Professional and Experience Requirements for Academic Staff", and "Suggestions on the Criteria for Basic, Good, and Outstanding Levels of Teaching". The documents determine the promotion and expectations of the position of Assistant Professor at the University. Job specifications laid down by the Centre were also studied. All the documents were then compared.

2.1.2 Diary Entries. A journal of the daily practice of an Assistant Professor (the researcher of the study) in the Centre was reviewed. The findings were analysed to identify the various dynamic aspects of role in that particular position.

- Work Diary. The usefulness of journals of work activities has been recognised in a number of management studies (Symon, 1998). For the present study, there were three reasons to choose a work diary to complement the information gleaned from official documents. First, the diary study allowed access to daily behaviour in a less obtrusive manner; second, the diary captured experiences immediately - the latest timing being at the end of the working day; third, a record of the work account (from October 23 to November 27), revealed some not-so-obvious or easily forgotten events. The objectives of the diary study were to reflect a daily flow of activity, obtain a clear picture of the diarist's daily activities, and identify a range of activities that might contribute to a better understanding of the roles played by the Assistant Professor. Excerpts from the diary are included in the Appendix.

- The Diarist as researcher. The diarist-as-researcher methodology adopted for this study is based on the rationale behind the practitioner-as-researcher in educational action research, which has been well documented and described in educational literature (Carr \& Kemmis, 1986; Titchen \& Binnie, 1993). Research carried out by a practitioner-as-researcher has been welcomed by educational professionals who see it as relevant, appropriate, and meaningful when issues are explored, analyzed, reflected, and interpreted for a particular purpose in a specific context. The diarist-as-researcher approach enjoys some more advantages -- the benefits of being able to break down the barrier between the research and the researched, allowing the study to be conducted in both reflective and empirical modes. In the present study, the diarist/researcher was the position-holder who recorded her daily activities at work. This diarist/researcher approach could help (a) remove possible misreading of the interpretative data generated from diary methodology; (b) avoid problems, such as attrition (i.e. respondents' failure to complete the study) or missing data; and (c) ensure the accuracy of diary entries.

\section{Analysis and Discussion of Findings}

A close examination of the data gathered for this research revealed five major role aspects in the official position under study: position and performance expectations, position and role structures, role performance, interrelationships and authority. 


\subsection{Position and performance expectations}

Figure 1 displays the University's positions and their corresponding performance expectations.

Every academic staff member is expected contribute to the professional area of work and instructional practices at the department or centre. $\mathrm{S} /$ he is expected to devote $60 \%$ of her/his time/workload to teaching and learning, $30 \%$ to research and scholarship, and $10 \%$ to other related activities, reflecting the 'pivotal', 'relevant', and 'peripheral' (Schein, 1971) values of job role attributes in these areas respectively. It seems clear that success of an Assistant Professor at the University is determined by his/her influence in the academic community. Formal academic activities and informal colleague groups (including research publications, conference presentations, and consultancy) are the major sources of information on the professional expertise of the Assistant Professor's academic work. 'Teaching and Learning' and 'Research and Scholarship Activities' constitute $90 \%$ of the official total workload, leaving only $10 \%$ to management, administration, and professional services for the public. The official performance expectations regarding the position of Assistant Professor do reflect this attitudinal attribute of professionalism.

Figure 2 is on the structure of the Centre with regard to the official positions. The pyramid representation mirrors a hierarchy of authority at the Centre, which was manifested in many of the work practices. The course syllabus, teaching materials and schedules, and student assessments were all pre-structured, leaving classroom teachers (most of whom were Instructors) not as much professional autonomy as they might have wanted. Tasks were delegated by the Centre and the division of labour was quite clear. The Curriculum, Material and Assessment Committee (CMA) also devised rules and procedural specifications for all the courses.

Table 1 shows the various duties and responsibilities of the diarist/researcher, among which were those related to the jobs of being a faculty co-ordinator and chairperson of the committee on self-funding activities at the Centre.

As an Assistant Professor at the Centre, the diarist/researcher of this study performed the role of a faculty co-ordinator. Please refer to Figure 3. A faculty co-ordinator had to make sure that the teachers working closely with her understood all aspects of the organisational control and followed the procedures devised by the CMA when dealing with course-related matters. The job specifications of a faculty co-ordinator show the importance of management skills, as the list of official duties uses verbs of performance such as 'monitor', 'ensure', and 'allocate'.

Other roles that the diarist/researcher performed within the Centre included organising self-funding courses on and off campus, and exploring revenue-generating possibilities in both educational and business circles. As the Chair of the Self-funding Activities Committee, she aimed to introduce initiatives to market the professional expertise of the Centre to meet the needs and demands of the University and the community at large.

While the University expects an Assistant Professor to demonstrate academic leadership qualities in terms of influence or impact of contribution in the academic community, the Centre also expects that same person to demonstrate management leadership qualities in enforcing the policies of the Centre and exercising the implicit authority given in the Centre's hierarchy structure. Clearly, these could be two very different role performance expectations that refer to the same position.

\subsection{Position and role structures}

The position structure of the Centre is shown in Figure 4, along with the responsibilities of the positions.

Figure 4 shows the control structure of the Centre. The CMA Committee standardised the syllabi, learning materials, and assessment of all the programmes offered at the Centre; the QAC formalised the procedures for programme evaluation; the Strategic Planning Committee (SPC) centralised the essential decision-making function of the Centre. Many of the role specifications and prescriptions were aimed at achieving three major operational aspects of the Centre: Standardisation of procedures, formalisation of the documents, and the centralisation of decisions. Faculty co-ordinators acted as links between the decision-making committees and the classroom teachers, who then had to implement the policies determined by the committees. However, faculty co-ordinators were very often members of various committees at the Centre, as were a few language instructors (who were classroom teachers). Thus, the control structure only shows the expected line of control or authority, not the actual operations. The notion of 'loose coupling' (Paisey 1992) befits the description of this position structure and its responsibilities. Flexibility and even frequent re-distribution of duties among committee members were characteristics of the operations within the various committees at the Centre.

The matrix structure in Figure 5, which is patterned on Paisey's matrix structure for school functions (1981), shows the diarist/researcher's various roles in her official position at the Centre and the role set. For example, the Assistant Professor's role as a faculty co-ordinator was concerned with all the duties at the operational level by 
managing instructional, academic, and administrative tasks; as Chairperson of the Self-funding Committee, the Assistant Professor had to collaborate with other units at the University and with organizations outside the University.

\subsection{Role performance}

Daily activities (the overt behavioural aspect) detailed in the diary reflect the diarist/researcher's conception of her role in the official position of Assistant Professor. The themes of the diary study between October 23 and November 24 (a sample of which is included in the Appendix) are ranked in order from most to least prominent as follows:

- Checking and answering e-mail

- Classroom teaching

- Pre- and post-class teaching and non-teaching matters (such as preparing materials for specific class needs, marking papers, double-marking other teachers' student work, and arranging special facilities or rooms for teaching purposes)

- Student consultation for assignment clarification, assignment feedback, pastoral care (emotional and English language problems)

- Informal meetings with teachers about classroom discipline, students' attitude problems, student complaints, student punctuality, etc.

- Strategic planning for self-funded courses in response to English language needs in the community

- Administrative matters related to the launching of new self-funding courses including holding committee meetings and liaising with the teachers and other units concerned

- Course management: Administrative matters related to teaching schedules, material development, handout distribution, assignment problems (such as plagiarism in students' written work and late submission), assessment details, grading parity across departments within the same faculty, and course/ material evaluation

- Liaison with host departments: Attended Course Committee Meetings as well as Staff Student Consultative Meetings in other departments; dealt with issues raised, such as those related to students' progress or performance, language or learning problems

- Other meetings in the Centre: Attended meetings with the Strategic Planning Group and the Curriculum, Material, and Assessment Committee

- Other Centre activities: Seminars, workshops, and extracurricular activities held by the Centre for various language teaching and learning purposes

- Research activities: Library work, preparing an academic article for publication

The themes reflect the position holder's attempt to fulfill both official and non-official role-norms ingrained in the Centre, which clearly requires someone to have leadership in management to ensure cohesion among staff members (as shown in the frequent informal meetings with teachers) and implementation of Centre policies (such as ensuring a uniformed teaching schedule and assessment parity across groups). Motivating teachers to work as a team and facilitating their course delivery were given priority in the diarist/researcher's agenda and description of her daily practice at work.

The meetings that the diarist/researcher had to attend gave some indication of the sources of role demand. The diarist/researcher had to deal with the Head of the Centre (in discussing and implementing Centre policies), the colleagues (in providing adequate resources for classroom teaching), other departments/units in the University (in attending to requests in Course Committee Meetings), and the students (in catering to their particular learning needs). In fact, all these sources of pressures and demand reflect the expectations that the community (such as employers of university graduates, the government and other funding bodies) have of the University in general and the Centre in particular regarding efforts to design and deliver courses to enhance students' English language skills.

Formalized role prescriptions could lead to moments of intra-role and inter-role conflict, as well as role ambiguity. The complexity and hierarchical nature of job responsibilities might create some intra-role conflict when the diarist/researcher's professional expertise led her to believe certain courses should have been more rigorously researched while at the same time her management mandate dictated a time frame and resource constraint. Inter-role conflict was evident when she had to perform a balancing act to deal with pedagogy issues 
raised by some teachers (e.g. inadequate input time for a learning outcome as perceived by individual teachers because of students' poor punctuality in classes) and management issues to achieve equity (e.g. conforming strictly to an assessment schedule to ensure parity and fairness of assessments across different groups of students).

Inter-role conflict was also evident in some situations. When the diarist/researcher performed her duties to generate income for the Centre through running self-funding activities, she changed her role from an academic to a business-oriented staff member who was engaging in decision-making processes that could sometimes relegate educational aims or goals to a position secondary to economic factors. The diarist/researcher also experienced a certain amount of role ambiguity when representing the Centre in the capacity of Faculty Coordinator at meetings with other academic departments to discuss or negotiate details relating to matters that were beyond course level. After all, she was only a coordinator and might not be equipped with the necessary information that was required for meaningful dialogue at these meetings.

The diarist/researcher was acting like an educational middle leader - part-academic, part-teacher, part-administrator. Her roles and responsibilities were diverse and complex. The scope of this middle leadership position very much illustrates Sergiovanni's (1984) three leadership roles -- technical, human and educational, all of which are crucial to the overall competence and efficiency of the work unit. The technical role is concerned with management duties and routines for daily operations; the human role focuses primarily on support and care for others to let them realize their on-the-job potential; the educational role is related to the role of being an 'expert' or someone more experienced in terms of knowledge and skills.

At work, one often has to make choices or even compromises among different forces. The daily diary entries of the study show the overt behavioural aspect of an Assistant Professor. The low frequency of research activities in the entries is indicative of the low priority given to academic pursuits, suggesting a failure to conform to the official role requirement regarding scholarly activities among the academic staff. A close study of the diary entries also clearly shows some tension between having to meet the official role requirements and the actual on-the-job requirements as perceived by the diarist/researcher. There seems to be a lack of compatibility between the University-wide directives and actual practice, which may give rise to potential role conflict (Biddle, 1970). According to previous studies, this difference between the expected and perceived roles can also easily give rise to role stress, which may lead to job tension or job dissatisfaction (Lee, 1997; Jones 1993), or result in role uncertainty (Mayers \& Zepeda , 2002)

\subsection{Interrelationships}

One of the prominent activities in the diary daily entries was the checking and responding to correspondence. The diarist/researcher spent on average half an hour every day responding to e-mails from colleagues, students, or host departments. This activity constituted an important part of her daily routine. Her promptness in responding to messages (usually within a day or even the hour) could have a bearing on the diarist/researcher's professional image of being informed, efficient, helpful, and decisive in her role network (e.g. in dealing with instructors and other departments or units) -- some essential qualities of leadership. The style of communication in the e-mails to her colleagues ranged from semi-formal to informal; the purposes of these communications ranged from sending group emails (for example, announcing information) to individual emails (for example, intimate 'pep' talks). The frequent communications with colleagues concerning teaching/learning issues reflects the collegiality in the Centre. The free expression of opinions and unsolicited suggestions in e-mails was not uncommon, indicating an open and participative approach to the Centre's work and a facet of the Centre's norms, values and beliefs (Harrison \& Shirom, 1999).

\subsection{Authority}

Diary entries reflect a wide scope of work but not necessarily the much needed authority to carry out the duties involved. Role conflict and ambiguity easily arose when the diarist/researcher was dealing with teacher complaints about students, for example. Since the diarist/researcher was only a coordinator, did she have authority over classroom management or disciplinary issues? Since the coordinator had to evaluate teacher performance and give her opinion when it came to making decisions on issues related to teacher professional development or service terms with the Centre, did the duty imply that the coordinator should have a certain amount of 'authority'? The concept of authority has not been thoroughlydealt with in official documents regarding implementation of policies, resulting in ambiguity in carrying out some policy measures.

\section{Limitations}

This study is a piece of insider research (as the researcher is also the subject of the research) which may lead to a 
fuzzy boundary between the researcher and the researched. However, since the researcher is more familiar with the context of the study, the authenticity of information can be enhanced. As this study only focused on a single unit in an institution, the findings cannot be generalized to other institutions. Future research could aim at involving more units or units in different academic institutions for comparison purposes in order to gain a more complete picture of academic work life.

\section{Conclusion}

The present study shows that official positions in an organisation may not accurately reflect the required professional qualities and skills or the roles that the position holders are playing at a work unit in that organization. The roles performed by a position-holder in a work unit (e.g. the role of coordinating administrative and academic matters of faculty by an assistant professor in the study) are made possible because clear job guidelines (i.e. the specific duties or tasks) and responsibilities (i.e. to whom and for what one should be responsible) are spelled out by the work unit. Yet, how the holder of a position interprets job specifications, how $\mathrm{s} / \mathrm{he}$ sees the relationship between the ones to whom or for what $\mathrm{s} / \mathrm{he}$ is responsible, and how $\mathrm{s} / \mathrm{he}$ makes choices and decisions in carrying out those duties depends on his/her perception of expectations in the work environment. These perceived and enacted roles are affected by and reflecting the culture (including individuals' personalities and dispositions) in a specific work context, pointing to the importance of understanding work culture in order to appreciate job practices. A case in point is a seemingly odd decision made by an academic in this study to put intellectual pursuits in the back burner.

An appreciation of job practices could prompt one to start re-thinking if there should be a more appropriate re-alignment of position and role. While 'multi-tasking' is a buzzword, a re-conceptualisation of a position title that corresponds with role performances to meet with the challenges of the changing time in which the organization or work unit is situated could help enhance job satisfaction and further promote professionalism. An analysis of a single position in this study has weaved a colourful role tapestry for the individual in that position. Indeed, it is the role, not the position, that reveals the dynamic aspects of a work environment, thus presenting a dimension that is both organic and human in the analysis of organisational work.

The present study elicits differences in the concepts of roles and positions; however, the researcher has only included one subject in her investigation of a particular position in an organisation. There was no attempt to search for or to examine any data that might lead to a definitive conclusion on any aspect of roles and positions. The study has only conducted a closer inspection of an individual's roles and her official position. Although this aim was limited, it is hoped that the insight presented in this paper will lead to a further analysis of roles and positions in the workplace. It is also hoped that the study can contribute some idea to a discussion about the relationship between staff professional development and the growth of an organization or that it can act as a departure point for a re-examination of important issues such as staff training and manpower planning for the changing and evolving job requirements of an existing or new official position.

\section{References}

Bates, A. (1998). Restructuring the university for technological change. [Online] Available: http://bates.cstudies.ubc.ca/carnegie/carnegie.html

Biddle, J. (1979). Role Theory (Expectations, identities, and behaviors). New York: Academic Press, Inc.

Carr, W. and Kemmis, S. (1986). Becoming Critical: Education, Knowledge and Action Research. London: Falmer Press.

Grace, G. (1972). Role Conflict and the Teacher. London: Routledge \& Kegan Paul.

Goffman, E. (1961). Encounters: Two Studies in the Sociology of Interaction. Bobbs-Merrill Company, Inc., NY. U.S.

Guy, M. (1985). Professionals in Organizations: Debunking a Myth. New York: Praeger.

Hales, C.P. (1993). Managing through organization. London: Routledge.

Ham, C. \& Hill, M. (1993). The Policy Process in the Modern Capitalist State. New York: Harvester Wheatsheaf.

Hammersley, M. (1992). Deconstructing the qualitative-quantitative divide, In Brannen, J. (ed.) Mixing Methods: Qualitative and Quantitative Research. Aldershot, Avebury.

Handy, C.B. (1985). Understanding Organizations, 3rd Edn. Harmondsworth, Penguin Books.

Harrison, M.I. \& Shirom A. (1999). Organizational Diagnosis and Assessment. Sage Publications, Inc. 
Hood, C. (1976). The limits of administration. London: Wiley.

Jones, M. (1993). Role conflict: cause of burnout or energizer? Soc. Work, 38:136-141.

Judge, T, Boudreau, J. \& Bretz, R. (1994). Job and life attitudes of male executives. Journal of Applied Psychology, 79, 767-782. http://dx.doi.org/10.1037/0021-9010.79.5.767

Lachman, R. \& N. Aranya. (1986). Job attitudes and turnover intentions among professionals in different work settings, Organization Studies,7(3): 279-293. http://dx.doi.org/10.1177/017084068600700305

Lee, D. (1997). Employee stress. John Liner Rev, 11: 3-7.

Levinson, D. (1959). Role, personality and social structure in the organizational setting, in G. Salaman \& K. Thompson (Eds) People and Organisations (pp.223-237). Longman: The Open University Press.

Mayers, R.S. \& Sepeda, S.J. (2002). High school department chairs: role ambiguity and conflict during change. National Association of Secondary School Principals. NASSP Bulletin, 86(632), 49-64. http://dx.doi.org/10.1177/019263650208663205

McCalley, R. (2002). Patterns of Management Power. Westport, Conn.: Quorum Books.

McInnis, C. (1998). Change and continuity in academic work, Higher Education Series Report No. 30, Department of Employment, Education, Training and Youth Affairs.

McKenna, E. (2006). Business Psychology and Organisational Behaviour. Psychology Press.

Paisey, A. (1981). Organization and Management in Schools: Perspective for Practising Teachers. London: Longman.

Paisey, A. (1992). Organization and Management in Schools: Perspectives for Practising Teachers and Governors. London: Longman.

Raelin, J. (1986). Clash of Cultures: Managers and Professionals. Boston: Harvard Business School Press.

Ruddock, R. (1969). Roles and Relationships. London: Routledge \& Kegan Paul.

Sarros, J. C., Gmelch, W.H. \& Tanewski, G.A. I. (1996). Role stress and satisfaction of academic department heads. Frankston, Victoria, Australia: Monash University.

Schaubroeck, J. Cotton, J. \& Jennings, K. (1989). Antecedents and consequences of role stress: a covariance structure analysis. Journal of Organisational Behavior. 10, 35-58. http://dx.doi.org/10.1002/job.4030100104.

Schein, E.H. (1971). The individual, the organization and the career: a conceptual scheme. Journal of Applied Behavioural Science, 7 (4), 401-426. http://dx.doi.org/10.1177/002188637100700401

Sergiovanni, T. (1984). Leadership and excellence in schooling. Educational Leadership, 41(5), 4-14.

Sergiovanni, T. (1989). Value-driven schools: the amoeba theory, in Walberg, H. and lane, S. (eds), Organising for learning: Towards the $21^{\text {st }}$ Century. Virginia: National Association of Secondary School Principals.

Silverman, D. (1970). The Theory of Organizations. London: William Heinemann Ltd.

Sonnenstahl, W. \& H. Trice. (1991). Linking organizational and occupational theory through the concept of culture. Research in the Sociology of Organizations, Vol. 9 edited by S. Bacharach. Greenwich, CT:JAI Press.

Sorensen, J. \& T. Sorensen (1974). The conflict of professionals in bureaucratic Organizations. Administrative Science Quarterly, 19, 98-106. http://dx.doi.org/10.2307/2391790

Symon, G. (1998). Qualitative research diaries, in G. Symon \& C. Cassell Qualitative Methods and Analysis in Organizational Research. Sage Publications.

Titchen, A \& Binnie, A. (1993). A unified action research strategy in Nursing. Education Action Research, 1, 25-33. http://dx.doi.org/10.1080/0965079930010103 


\section{Appendix}

Journal of daily activities at work

November 13 (Monday)

9:00 -- 10:30 am

reviewed teaching materials and students' work

$10: 30--12: 30 \mathrm{pm}$

timetabled class teaching

$12: 30-1: 30$

lunch

$1: 30-2: 30$

timetabled class teaching

$2: 30-4: 30$

$4: 30-5: 30$

talked to colleagues about a possible self-funding activity

discussed with a colleague possible of sending in a proposal to conference

November 14 (Tuesday)

8:30 -- 9:00 am

9:00-10:15

went through emails

10:30 -- 11:30

library work (ref conference paper)

11:30 -- 12:30 pm

timetable class teaching

$12: 30-1: 30$

timetable class teaching

$1: 30--2: 30$

classroom observation (for new teacher)

$2: 30--3: 30$

$3: 30--5: 30$

lunch

marked papers (double marking) \& prepared teaching materials

tidied up teaching/learning materials in the previous teaching hours

November 15 (Wednesday)

9:00 -- 10:00 am

10:00 -- 11:30

$11: 30--12: 30 \mathrm{pm}$

$12: 30--1: 30$

$1: 30--2: 30$

$2: 30--3: 30$

$3: 30--4: 30$

$4: 30--5: 15$

$5: 30--6: 30$

November 16 (Thursday)

9:00 -- 10:00 am

10:00 -- 10:30

$10: 30--1: 30 \mathrm{pm}$

$1: 30--1: 45$

$1: 45--2: 30$

$2: 30--3: 30$

$3: 30--5: 00$

marked papers (short essay \& double marking)

discussed long essay with a colleague; made copies for referencing

lunch

prepared materials for class teaching

2 students dropped in for consultation (re written assignments)

tied up materials in previous class hour; continued marking

went through documents related to course/syllabus meeting at 5:30 pm

early dinner

meeting

sent colleagues the notes on the course/syllabus meeting

met teachers about students' work progress \& students' absence

self-funding promotional materials

dealt with S's complaints about student's failure to observe punctuality. Decision:

talk to host department informally

lunch

timetabled teaching hour

marked papers (doublemarking)

3 students dropped in for consultation

\section{November 17 (Friday)}

9:00 -- 9:30 am

student tutorials (on long essay writing)

9:30 -- 10:30 marked papers (double marking)

$10: 30$-- 11:30 met a teacher about students' attendance problems

11:30 -- 12:15 p.m. lunch 


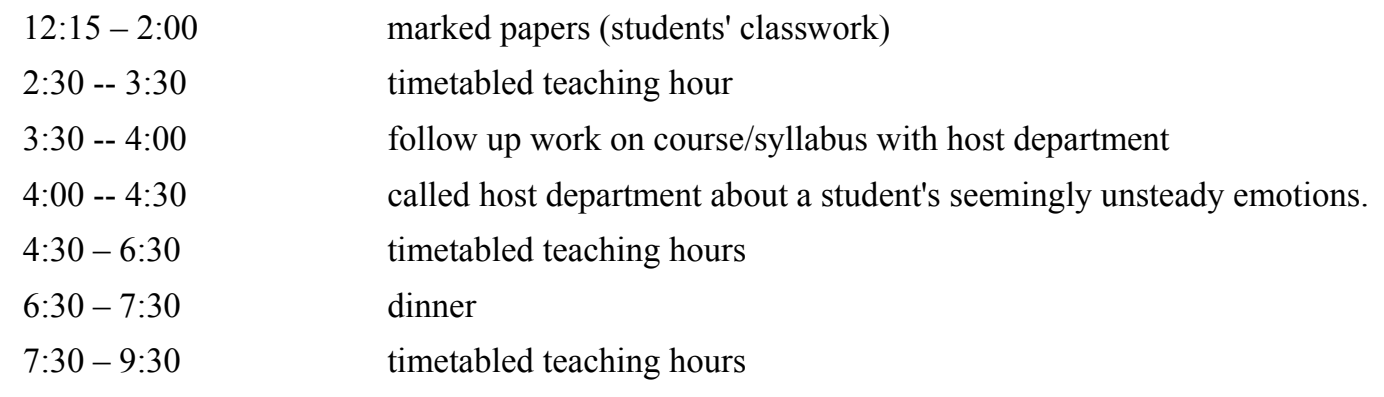

\section{November 20 (Monday)}

9:00 -- 10:00 am

10:00 -- 11:45

12:00 -- 1:15 pm

$1: 15-3: 15$

$3: 15--4: 00$

4:00 -- 5:00

November 21 (Tuesday)

$8: 30$-- 10:30 am

10:30 -- 11:30

$11: 30-1: 30 \mathrm{pm}$

$1: 30-2: 30$

2:30 -- 3:30

$3: 30$-- 5:30

November 22 (Wednesday)

8:30 -- 9:00 am
9:00 -- 10:30
10:30 -- 11:00
11:00 -- 2:45pm
2:45 -- 3:30
3:30 -- 6:30

6:30 -- 9:00

November 23 (Thursday)

8:30 -- 9:30 am

9:30 -- 10:45

10:45 -- 11:30

$11: 30$-- 12:45 pm

$12: 45-1: 30$

$1: 30-2: 30$

$2: 30--3: 30$

$3: 30$-- 5:00 checked e-mails, marked papers

CMA Meeting

lunch

marked \& double-marked papers; prepared materials for classroom teaching the following day; returned and made a few phone calls on arranging self-funding courses

3 students dropped in for consultation on assignment

library work for own paper

timetabled teaching hours

tidied up teaching materials/ checked $\&$ answered e-mails

timetable teaching hours

lunch

prepared teaching materials/ double marking

timetable teaching hours

checked mail; double mark; room arrangement for OP

meeting with P. about new policies in Centre

brunch

double mark; see student about OP

late lunch

see students about OP, marking papers, prepare teaching materials, checked/answered e-mail, collected grades from teachers for parity for the lst assignment

timetabled teaching hours

(university class teaching suspended)

checked/ answered e-mails

checked grades across groups for first assignment

talked with B. about students' complaint of assessment in first assignment

prepared spreadsheet to show all scores and analysed their distribution

lunch

talked with $\mathrm{T}$. about promotional materials

talked with A. (SPEED) about promotional materials for self-funding courses; made notes on the progress of the self-funding course arrangement

marked and double marked written assignments 
Table 1. Some responsibilities undertaken by a holder of the position 'academic professor'

\begin{tabular}{|l|l|}
\hline Types of responsibility & Examples of aims and activities \\
\hline Administrative & $\begin{array}{l}\text { Aim: Ensure smooth operation } \\
\text { Activities: Having regular meetings with teachers; attending to students' } \\
\text { class attendance issues }\end{array}$ \\
\hline Curriculum & $\begin{array}{l}\text { Aim: Maintain continuity and progression } \\
\text { Activities: Discussing and negotiating with other academic units regarding } \\
\text { programme development }\end{array}$ \\
\hline Teaching & $\begin{array}{l}\text { Aim: Initiate, build on and share innovative and/or effective teaching } \\
\text { practices } \\
\text { Activities: Material design and preparation in collaboration with colleagues } \\
\text { at the Centre and those in other academic units }\end{array}$ \\
\hline Management of Student Learning & $\begin{array}{l}\text { Aim: Facilitate student learning } \\
\text { Activities: Incorporating an on-line platform into courses for independent } \\
\text { learning and building up sources materials for student reference }\end{array}$ \\
\hline Self-financing Activities & $\begin{array}{l}\text { Aim: Generate revenue } \\
\text { Activities: Exploring market opportunities and setting up a quality } \\
\text { assurance mechanism }\end{array}$ \\
\hline
\end{tabular}

\section{Positions and performance expectations in three activity blocks}

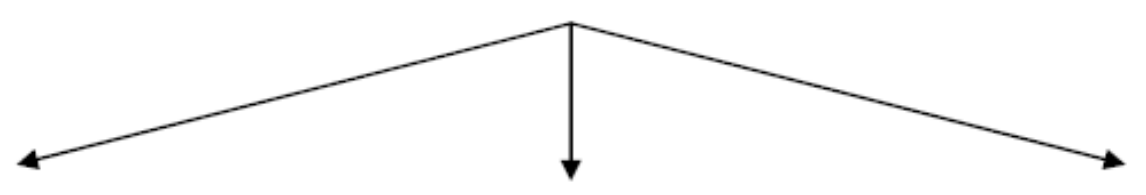

Teaching \& Learning

Research \& Scholarship

Other Rel evant Activities

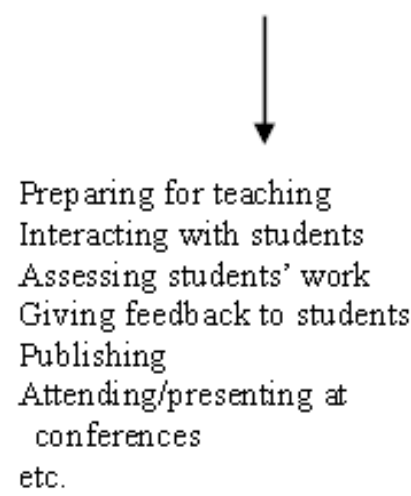

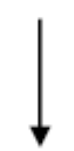

Research supervision

Publication

Research grant activities

Creative activity

Learning \& teaching grant

activities

High- level consultancy

etc.

Figure 1. Position of assistant professor and performance expectations at university

(Extracted from University's staff performance appraisal documents) 


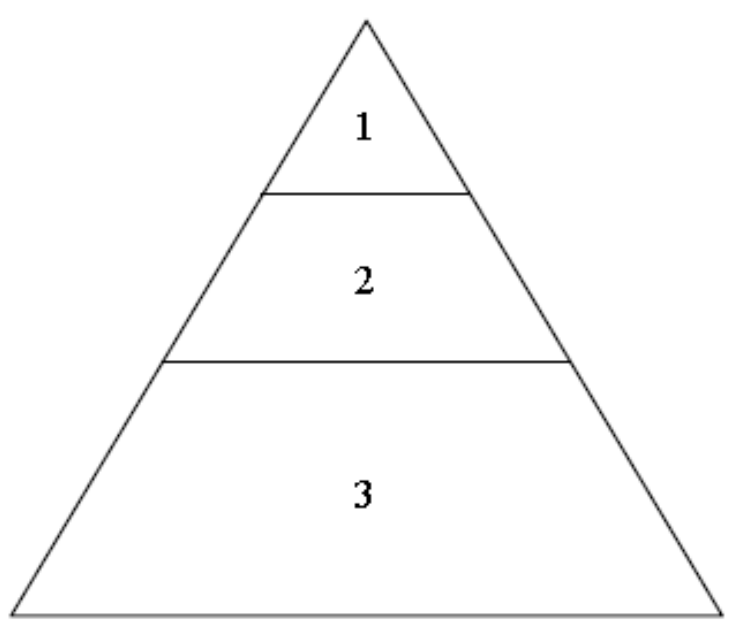

Figure 2. Pyramidal Representations of Official Positions

(N.B. 1 = Head; 2 = Senior Staff (including Principal/Senior Lecturers and Lecturers; Assistant Professors); 3 = Language Instructors)

\section{Job Specifications for Faculty Co-ordinator held by an Assistant Professor}

To be ultimately responsible to the Head for the delivery of credit-based subjects to students of a nominated faculty and to:

(1) Allocate responsibilities to the Faculty sub-co-ordinators depending on the composition of programmes/ departments within the nominated Faculty. (M)

(2) Ensure familiarity with each of the host department programmes within the Faculty. (M)

(3) Sample each of the courses within the Faculty by teaching on a planned 'rotational' basis classes offered within the Faculty over a period of a year. $(\mathrm{T})$

(4) Teach at least one class outside the nominated Faculty. (T)

(5) Ensure suggested teaching schemes and teaching approaches are available. (T) \& (M)

(6) Meet with the Faculty sub-co-ordinator and staff who are teaching classes related to the relevant Faculty. (T) \& (M)

(7) Review student feedback on courses and respond accordingly. (M)

(8) Monitor assessment procedures. (T) \& (M)

(9) Ensure that Faculty's programme committee meetings are attended as requested. (M)
$(\mathrm{M})=$ Management
$(\mathrm{T})=$ Teaching
No. of teaching hours $=10$

No. of student groups to co-ordinate $=42$

No. of teachers to co-ordinate $=15$

Figure 3. Performance expectations at the Centre 


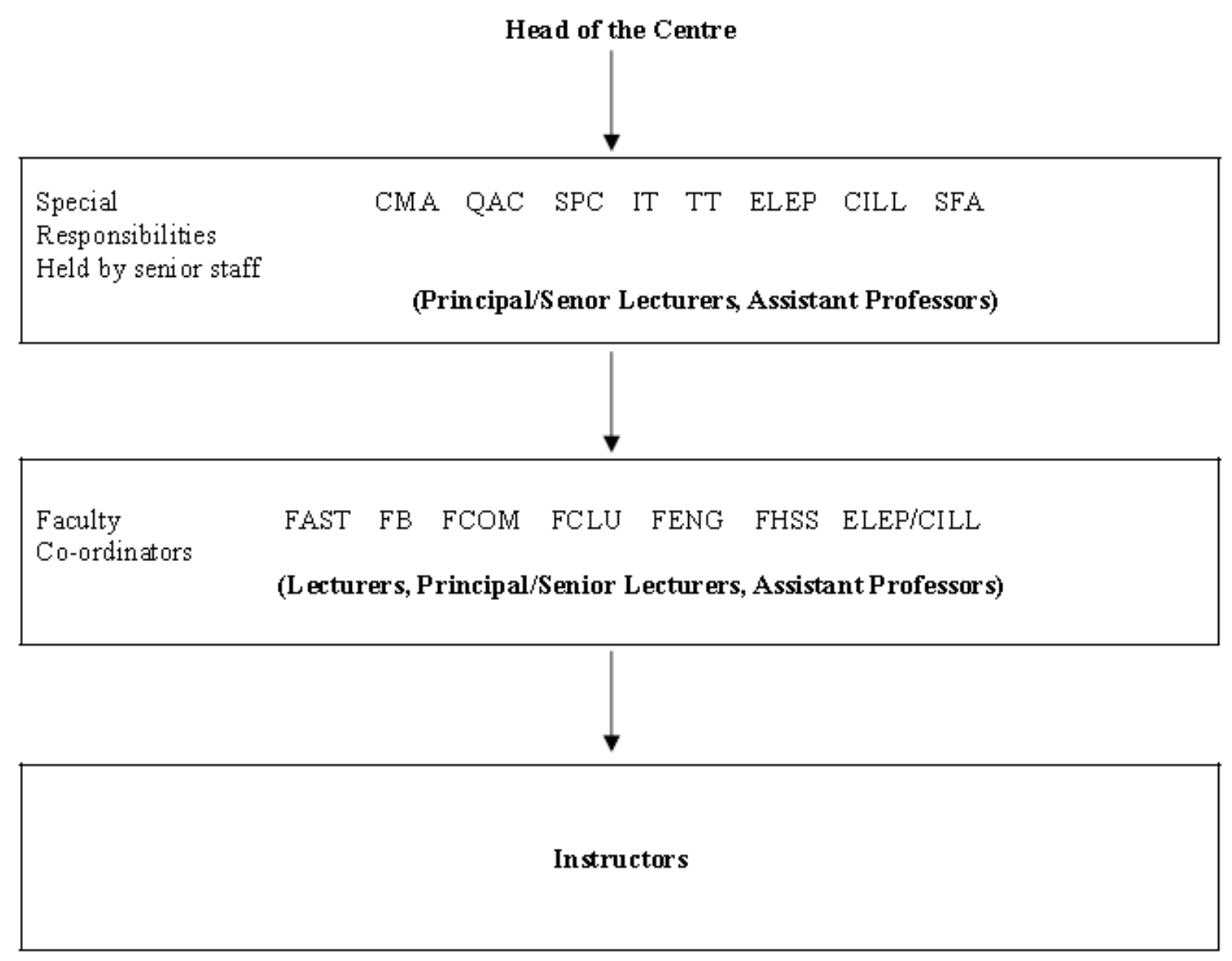

Figure 4. Hierarchical Structure of the Centre (showing responsibilities for each official position)

(N.B. Official positions at the University are in bold type.)

$\mathrm{CMA}=$ Curriculum, Material and Assessment Committee

$\mathrm{QAC}=$ Quality Assurance Committee

$\mathrm{SPC}=$ Strategic Planning Committee

IT $=$ Information Technology

$\mathrm{TT}=$ Timetabling

ELEP $=$ English Language Enhancement Programme

$\mathrm{CILL}=$ Centre for Independent Language Learning

$\mathrm{SFA}=$ Self-funding Activities

FAST, FB, FCOM, FCLU, FENG, FHSS = acronyms for six faculties at the University 


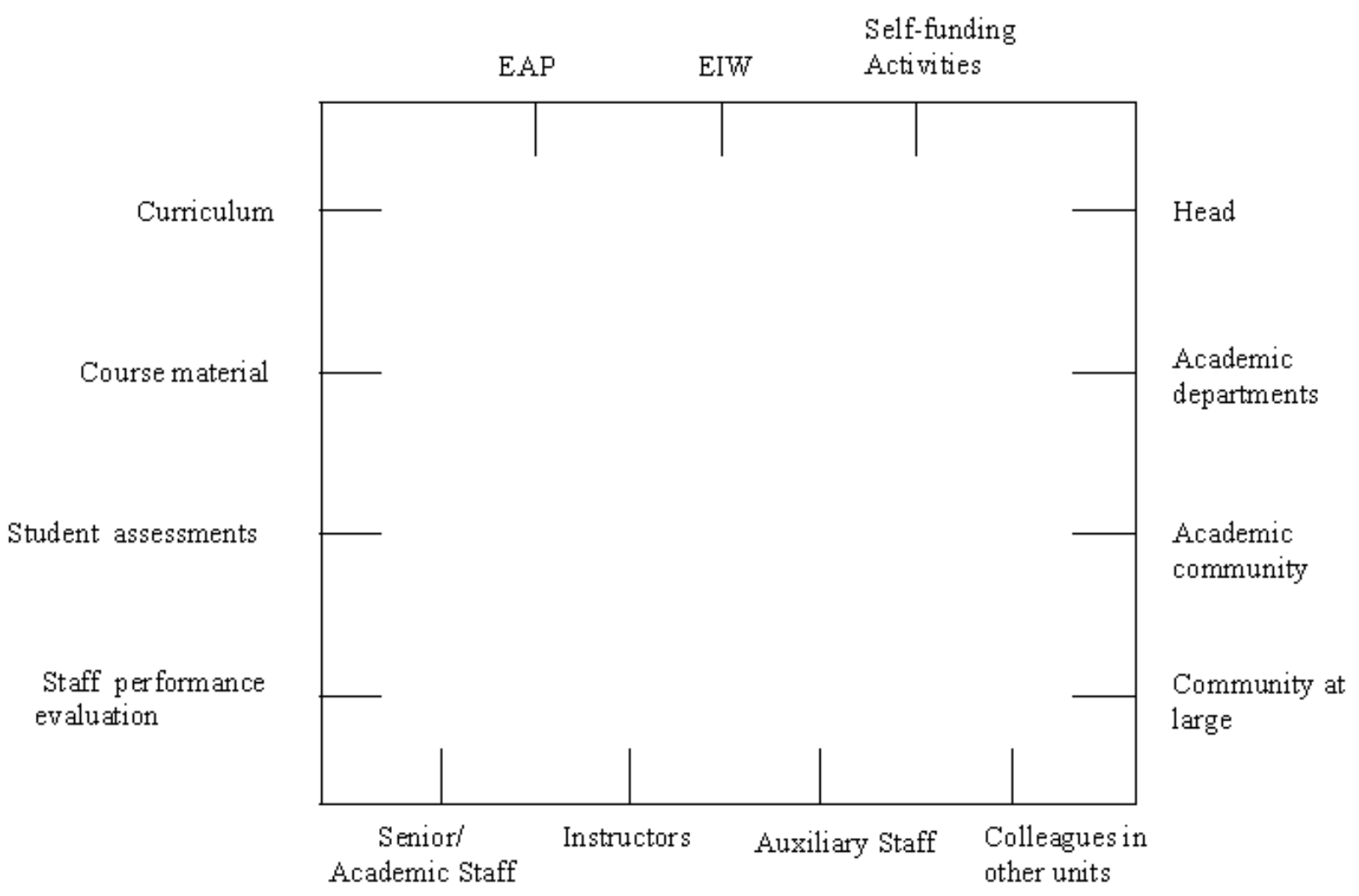

Figure 5. Matrix structure for the roles or functions of an Assistant Professor (the diarist/researcher) 